\title{
Left Main Coronary Angioplasty: Assessment of a "Risk Score" to Predict Acute and Long-Term Outcome
}

\author{
MICHEL SAMSON, M.D.,* SYLVAIN PLANTE, M.D., HANNIE MEESTER, M.D., \\ BENNO J. RENSING, M.D., PIM J. DE FEYTER, M.D., and PATRICK W. SERRUYS, M.D. \\ From the *Department of Medecine, Quebec Heart Institute, Laval University, Quebec, \\ Canada and the Thoraxcenter, Erasmus University, Rotterdam. The Netherlands
}

\begin{abstract}
Due to the recent emergence of adjunctive techniques such as cardiopulmonary bypass support, left main angioplasty may become more routinely applied in the near future. In order to choose the best possible therapy, a precise risk assessment will be desirable. Twenty-two left main angioplasties were thus reviewed and patients were divided in two groups according to a risk score adapted from a previously published jeopardy score. Group I included patients with a risk score $\leqslant 6$ and group II patients with a risk score $>6 . A$ cutoff criterion of six points was chosen because it represents the maximal amount of myocardium put at jeopardy from a single coronary stenosis. The success rate of the procedure was $77 \%$ and was similar in both groups. Of the 12 patients in group I, two patients underwent in-hospital bypass surgery and one of them died. Among the ten patients of group II, one sustained a myocardial infarction, three underwent acute surgery, and one patient died postoperatively. After a mean follow-up of 41 months, the total mortality rate was $17 \%$ in group I and $30 \%$ in group II. The long-term event-free survival rate was $75 \%$ in group I and $10 \%$ in group II $(P=0.004)$. The risk score was found to be a potentially important predictor of sustained success (long-term success: $4.4 \pm 2.9$ vs no long-term success: $8.3 \pm 3.4 ; P=0.01$ ), although sophisticated statistical analysis was limited by the small number of patients. Thus, in patients with a low risk score, angioplasty seems to be an appropriate treatment while it appears that surgery should remain the standard therapy for patients with a calculated high risk score. However, the clinical significance of this new risk score remains to be determined with more elaborate statistical analysis applied to a larger number of patients. ( $\mathrm{J}$ Interven Cardiol 1990:3:2)
\end{abstract}

\section{Introduction}

Over the past two decades, left main (LM) coronary artery disease has been considered the exclusive territory of the cardiac surgeon and one of the major contraindications to percutaneous transluminal coronary angioplasty (PTCA). ${ }^{1}$ Clinical stud-

Dr. Plante is the recipient of grant \#880268 from the Quebec Health Research Foundation (FRSQ), Montreal, Quebec, Canada.

Address for reprints: Patrick W. Serruys, M.D., Catheterization Laboratory, Thoraxcenter, Erasmus University, P.O. Box: 1738, 3000 DR Rotterdam, The Netherlands.

Submitted for publication March 2, 1990; accepted with revisions April 11, 1990; revisions received June 14, 1990. ies have indeed shown an overall though variable survival benefit in surgically treated patients in comparison to medically treated patients. However, as experience in PTCA grew, accompanied by technical improvements, increasingly classical contraindications to PTCA fell, with a rewarding clinical effect. ${ }^{2,3}$ To date, merely three studies have helped to clarify the risks and benefits of left main PTCA by stratifying the procedure in "protected" and "unprotected" according to the presence of a patent graft to the left coronary arteries ${ }^{4,5}$ and/or presence of collaterals to the left circulation. ${ }^{6} \mathrm{Al}-$ beit simple and informative, this classification remains somewhat imprecise, and because of the recent emergence of adjunctive techniques, such as the percutaneous cardiopulmonary bypass sup- 
port, ${ }^{7}$ a better assessment of the amount of myocardium at risk would be useful to adequately select the best therapy for these patients.

Accordingly, to achieve this goal, we modified the concept of the jeopardy score described by $\mathrm{Ca}$ liff et al., ${ }^{8}$ which excluded patients with LM disease, by incorporating into it the protective effect of collaterals and bypass grafts. This article presents our acute and long-term results with LM PTCA in relation to this "risk score" and discusses the available treatment options for LM disease.

\section{Methods}

Study Patients. Of 2,978 patients who had a PTCA procedure performed between September 1980 and June 1989, 22 patients underwent a PTCA of the LM and they constituted the study group. Information was obtained by telephone interviews, hospital databases, mailed questionnaires, and civil registries. The decisions to perform PTCA were always based on discussions involving the surgeon and one member of the PTCA team. Twelve patients had had previous bypass surgery. Of these, 11 patients, who had patent grafts to the left anterior descending artery (LAD) and/or the left circumflex artery (LCx), were considered to be at low risk of complications and were treated with PTCA. The remaining patient (patient 6) had a proximal total occlusion of the graft and was refused for surgery because he had an iatrogenic aortic dissection at the time of previous bypass surgery, for which a Dacron patch was installed in the ascending aorta. In the ten patients without previous bypass, preference was given to PTCA because of various medical conditions in six patients. These were: chronic renal failure (patients 1 and 21); age alone (patient 13); age associated with severe chronic lung disease (patient 22); severe peripheral artery disease (patient 3 ); and severe obesity (patient 18). Patient 14 was in cardiogenic shock and had an emergency PTCA. Finally, due to the retrospective nature of this study, no clear reasons for preferential treatment with PTCA could be identified in the remaining patients (patients 5, 12, and 16).

Definition of the Risk Score. Patients were classified according to a "risk score" derived from a jeopardy score previously described in the literature which has been shown to carry important prognostic information. ${ }^{8}$ For this purpose, all angiograms were reviewed by two members of the study team and a third one was involved when consensus could not be reached. The angiograms were reviewed without knowledge of patient's outcome. To calculate the score, the coronary circulation was divided into six segments (Fig. 1): the distal LAD, the major septal branch, the major diagonal branch, the distal $\mathrm{LCx}$, the major obtuse marginal branch and the right coronary artery (RCA). The RCA was not included in the calculation except if filled by collaterals from LAD and/or $\mathrm{LCx}$ because only then, did it participate directly in the risk of LM dilatation. Each segment distal to a stenosis $>50 \%$ was attributed 2 points if not filled retrogradely by collaterals from the RCA or a patent graft. In the presence of a left dominant system, the $\mathrm{LCx}$ was considered as three segments instead of two. Thus, the maximal score was 12 points, in which case there was filling of the RCA from the left circulation or a left dominant system, in addition to the stenosed LM. The minimal score was 2 points, in which case all segments, but one, were filled via patent grafts or collaterals from RCA.

After calculation of this risk score, patients were arbitrarily divided in two groups. Group I included patients with a risk score $\geq 6$ points and group II included those with a score $>6$ points. Six points was chosen as a convenient cutoff criterion because it is the maximal score obtainable from a single coronary artery stenosis (e.g., proximal LAD) and, therefore, anything greater than this implied an unusually high amount of myocardium at risk.

Clinical and Angiographic Characteristics of the Patients. The clinical and angiographic characteristics of the patients are indicated in Table I. Unstable angina was defined as crescendo angina, new onset angina of a progressive nature, angina at rest or early postinfarction angina as proposed by de Feyter. ${ }^{9}$ Vessel disease was classified as double when the LM stenosis was found with a dominant or balanced nonstenotic RCA. It was triple when the $\mathrm{LM}$ stenosis was accompanied by a $>50 \%$ stenosed dominant or balanced RCA or when there was a left dominance. ${ }^{2}$ Ejection fraction was calculated from the contrast ventriculography.

Procedural Approach. All angioplasties were 


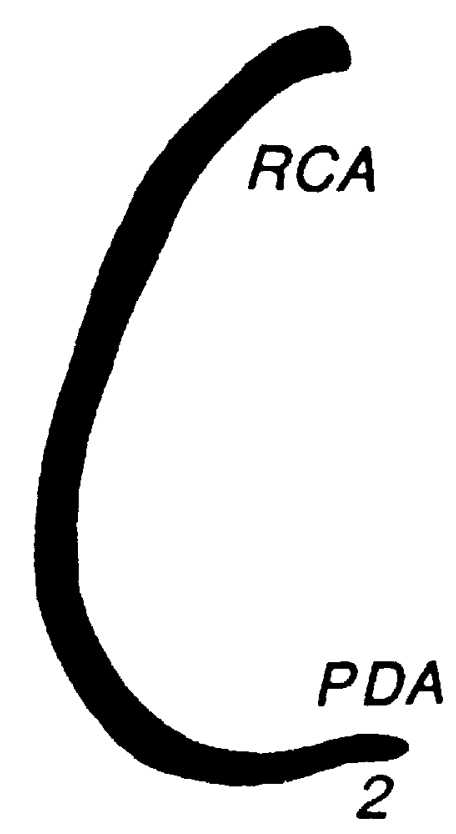

Figure 1. Calculation of the risk score. The coronary tree is divided into 6 segments to which 2 points are attributed when there is a $\geqslant 50 \%$ stenosis proximally. The protective effect of grafts and/or collaterals (arrows) is assessed. The right coronary artery is calculated only if its flow originates from the left circulation. (Diag = main diagonal branch; LCA = left coronary artery; Marg $=$ main obtuse marginal branch; PDA = posterior descending artery; Sept $=$ main septal branch.) performed according to the standard technique in use at the time. In three patients (patients 2,9 , and 13), the Sones technique from the right arm was used while the Judkins technique was used in the others. In patient 16 , the "kissing-balloon" technique ${ }^{10}$ was used and in patient 18 , two guidewires were used simultaneously (Fig. 2). Prophylactic insertion of intra-aortic balloon pump (IABP) was not used. Nevertheless, an IABP was required for two patients. The first one (patient 4) had the IABP already in place before the procedure because of refractory unstable angina and the second (patient 14) required it at the time of the PTCA because of cardiogenic shock. When multi-lesion dilatation was performed in a patient with a significant stenosis of a graft to the left coronary circulation, the graft was dilated first. Otherwise, the LM stenosis was always the first vessel dilated. Patients received $250 \mathrm{mg}$ intravenous acetylsalicylic acid and 10,000 IU of intravenous heparin prior to the procedure and they were treated with nifedipine and acetylsalicylic acid afterward. Angiographic success was defined as reduction in the stenosis severity to $<50 \%$ luminal diameter, as assessed by visual interpretation. Major complications were defined as death, acute bypass surgery and nonfatal Q- and non-Q-wave myocardial infarction (diagnosed using standard serum enzymes and electrocardiographic criteria).

Follow-up. Follow-up data were available for all patients surviving initial hospitalization. Angiographic follow-up of the patients was performed as clinically indicated. Restenosis was defined as a loss of at least $50 \%$ of the initial gain achieved. ${ }^{11}$ 
SAMSON, ET AL.

Table I. Clinical and Angiographic Characteristics of Patients with Left Main Stem Coronary Angioplasty

\begin{tabular}{|c|c|c|c|c|c|c|c|c|c|c|}
\hline $\mathrm{Pt}$ & $\begin{array}{c}\text { Age } \\
(\mathrm{yrs} \pm \mathrm{SD})\end{array}$ & Sex & $\begin{array}{l}\text { Anginal } \\
\text { status }\end{array}$ & $\begin{array}{l}\text { Old } \\
\text { AMI }\end{array}$ & $\begin{array}{l}\text { Old } \\
\text { CABG }\end{array}$ & $\underset{( \pm \mathrm{SD})}{\mathrm{EF}}$ & $\begin{array}{l}\text { Number } \\
\text { of VD }\end{array}$ & $\begin{array}{c}\mathrm{RCA} \\
>50 \%\end{array}$ & $\begin{array}{c}\text { Risk } \\
\text { score } \\
( \pm S D)\end{array}$ & Comments \\
\hline \multicolumn{11}{|c|}{ Group I (Risk Score $\leq 6$ ) } \\
\hline 2 & 47 & $\mathbf{M}$ & stable & - & $Y$ & 0.64 & 3 & $\mathrm{Y}$ & 4 & \\
\hline 4 & 62 & $\mathbf{M}$ & unstable & $\mathbf{Y}$ & $Y$ & 0.38 & 3 & $\mathrm{Y}$ & 6 & $\begin{array}{l}2 \text { weeks postinferior } \\
\text { AMI/IABP (angina) }\end{array}$ \\
\hline 7 & 63 & $\mathbf{M}$ & stable & $\mathbf{Y}$ & $\mathrm{Y}$ & 0.31 & 3 & $\mathbf{Y}$ & 2 & \\
\hline 8 & 73 & M & stable & - & $\mathrm{Y}$ & 0.54 & 3 & $\mathrm{Y}$ & 2 & \\
\hline 9 & 68 & $\mathrm{~F}$ & stable & - & $Y$ & 0.65 & 2 & - & 4 & \\
\hline 10 & 63 & $F$ & stable & $\mathrm{Y}$ & $\mathrm{Y}$ & N/A & 3 & $\mathrm{Y}$ & 2 & \\
\hline 11 & 60 & $\mathbf{M}$ & unstable & $\mathbf{Y}$ & $\mathrm{Y}$ & 0.24 & 3 & $\mathrm{Y}$ & 6 & \\
\hline 15 & 62 & $\mathbf{M}$ & stable & - & $Y$ & 0.57 & 2 & - & 6 & \\
\hline 17 & 60 & $\mathbf{F}$ & stable & - & $\mathrm{Y}$ & 0.57 & 2 & - & 2 & \\
\hline 19 & 72 & $F$ & unstable & $Y$ & $\mathrm{Y}$ & 0.59 & 3 & $\mathbf{Y}$ & 2 & \\
\hline 20 & 63 & M & stable & $\mathbf{Y}$ & $\mathrm{Y}$ & 0.52 & 3 & $\mathrm{Y}$ & 2 & \\
\hline 22 & 82 & $\mathbf{M}$ & unstable & $Y$ & - & 0.50 & 2 & - & 4 & $\begin{array}{l}\text { RCA gives good } \\
\text { collaterals to the } \mathrm{LAD}\end{array}$ \\
\hline Total & $65 \pm 8$ & $M=67 \%$ & Unst $=33 \%$ & $58 \%$ & $92 \%$ & $0.50 \pm 0.13$ & $3=67 \%$ & $67 \%$ & $3.5 \pm 1.7$ & \\
\hline \multicolumn{11}{|c|}{ Group II (Risk Score $>6$ ) } \\
\hline 1 & 61 & M & stable & - & - & 0.69 & 2 & - & 10 & \\
\hline 3 & 75 & M & stable & $\mathrm{Y}$ & - & 0.50 & 3 & $\mathbf{Y}$ & 12 & $\begin{array}{l}\text { LAD fills the occluded } \\
\text { RCA }\end{array}$ \\
\hline 5 & 49 & M & stable & - & - & 0.59 & 2 & - & 8 & \\
\hline 6 & 57 & $\mathbf{M}$ & stable & - & - & 0.65 & 3 & $\mathrm{Y}$ & 10 & $\begin{array}{l}\text { Proximal occlusion of } \\
\text { the graft }\end{array}$ \\
\hline 12 & 43 & $\mathbf{M}$ & stable & - & - & N/A & 2 & - & 10 & \\
\hline 13 & 73 & $\mathrm{~F}$ & unstable & $\mathbf{Y}$ & - & 0.78 & 2 & 一 & 8 & \\
\hline 14 & 71 & $F$ & acute AMI & - & - & 0.63 & 2 & - & 10 & $\begin{array}{l}\text { Ant.AMI/Shock/IABP/ } \\
\text { LM:total occlusion }\end{array}$ \\
\hline 16 & 41 & $\mathbf{M}$ & unstable & - & - & 0.76 & 2 & - & 10 & \\
\hline 18 & 79 & $\mathrm{~F}$ & stable & - & - & 0.59 & 3 & - & 12 & Left dominance \\
\hline 21 & 75 & $\mathbf{M}$ & unstable & $\mathbf{Y}$ & - & N/A & 3 & $\mathbf{Y}$ & 12 & $\begin{array}{l}\text { LCx fills the occluded } \\
\text { RCA }\end{array}$ \\
\hline Total & $62 \pm 13$ & $\mathrm{M}=70 \%$ & Unst $=40 \%$ & $30 \%$ & $10 \%$ & $0.65 \pm 0.09$ & $3=40 \%$ & $30 \%$ & $10.2 \pm 1.4$ & \\
\hline$P$ value & 0.6 & 1,0 & 1.0 & 0.2 & - & 0.01 & 0.4 & 0.3 & - & \\
\hline
\end{tabular}

$\mathrm{AMI}=$ acute myocardial infarction; Ant. $=$ anterior $\mathrm{CABG}=$ coronary artery bypass grafting; $\mathrm{EF}=$ ejection fraction; $\mathrm{F}=$ female; $\mathrm{M}$ $=$ male; $\mathrm{N} / \mathrm{A}=$ not available; $\mathrm{Pt}=$ patient Unst $=$ unstable; $\mathrm{VD}=$ vessel disease; $\mathrm{Y}=$ yes; $\mathrm{yrs}=$ years.

Risk score is defined in the text. $\mathrm{P}<0.05$ is considered statistically significant.

The need for additional revascularization with repeat PTCA or bypass surgery, anginal status, functional class (New York Heart Association-NYHA), anti-anginal medications and incidence of major events (death and myocardial infarction) were assessed.

Statistics. Statistical analysis was performed with the Fisher's exact test for discrete variables and the Student's $t$-test for continuous variables. Values are expressed as mean $\pm \mathrm{SD}$. Differences were considered significant at a probability value of $<0.05$.

\section{Results}

Table I shows the baseline characteristics. The only significant difference found between both groups was the lower ejection fraction of group I, $0.50 \pm 0.13$ compared with $0.65 \pm 0.09$ for group II 


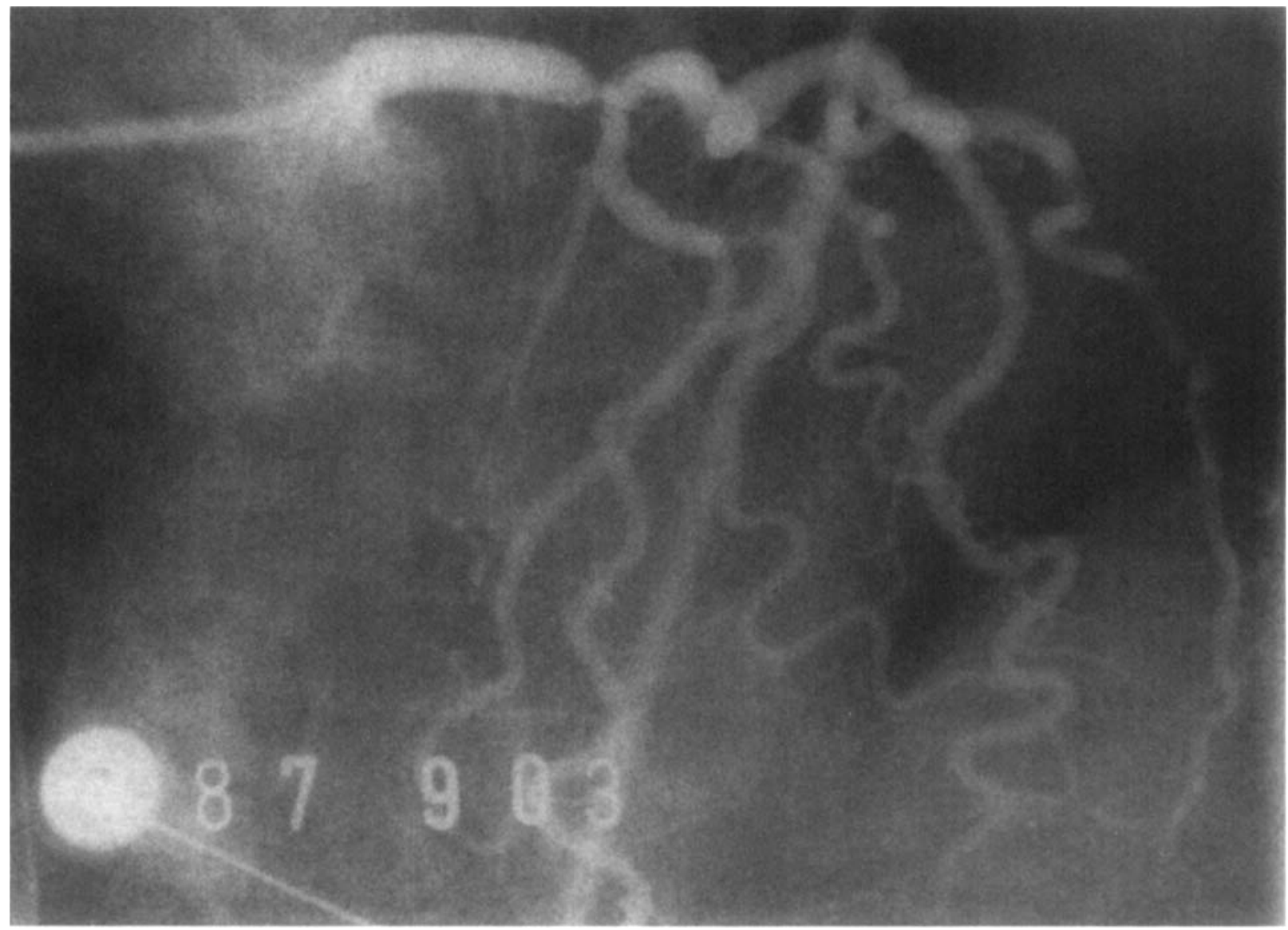

Figure 2A. Left main coronary artery stenosis involving the bifurcation in patient 18 .

$(\mathbf{P}=0.01)$. Table II lists the details of the procedures and the outcomes for each study patient. The angiographic overall success rate was $77 \%$ and was similar in both groups. One patient of each group died in-hospital after immediate bypass surgery. No other acute complications occurred in patients of group I. In group II, one patient required urgent surgery because of a $\mathrm{LCx}$ dissection, and another one sustained a nonfatal infarction. After a mean follow-up period of 41 months (range: $0.5-81$ months), one more patient of group I and two patients of group II died. Thus, the total mortality rate was $17 \%$ and $30 \%$ for groups I and II, respectively $(\mathrm{P}=\mathrm{NS})$. Figure 3 provides a general summary of the outcomes of each group. As shown, the long-term success of the two groups, defined as immediate angiographic success without any acute or late events, differed significantly from each other.
Long-term success was achieved in nine patients $(75 \%)$ of group I and in only one patient $(10 \%)$ of group II $(\mathrm{P}=0.004)$. Table III compares patients with and without long-term success. Sustained success was predicted by the risk score, when considered as a continuous variable (long-term success: $4.4 \pm 2.9$ vs no long-term success: $8.3 \pm 3.4$; P $=0.01$ ), and by history of previous bypass surgery (long-term success: $80 \%$ vs no long-term success: $33 \% ; \mathrm{P}=0.04)$. A follow-up angiogram was obtained at a mean time of $16.1 \pm 26.2$ months in eight patients $(40 \%)$ who survived the initial hospitalization. Four patients had a restenosis of the LM, of whom three patients necessitated bypass surgery. In the remaining patient, the dilated graft to the LAD was still patent. Among the four patients without $\mathrm{LM}$ restenosis, one had a restenosis of the dilated LAD for which a re-PTCA was per- 


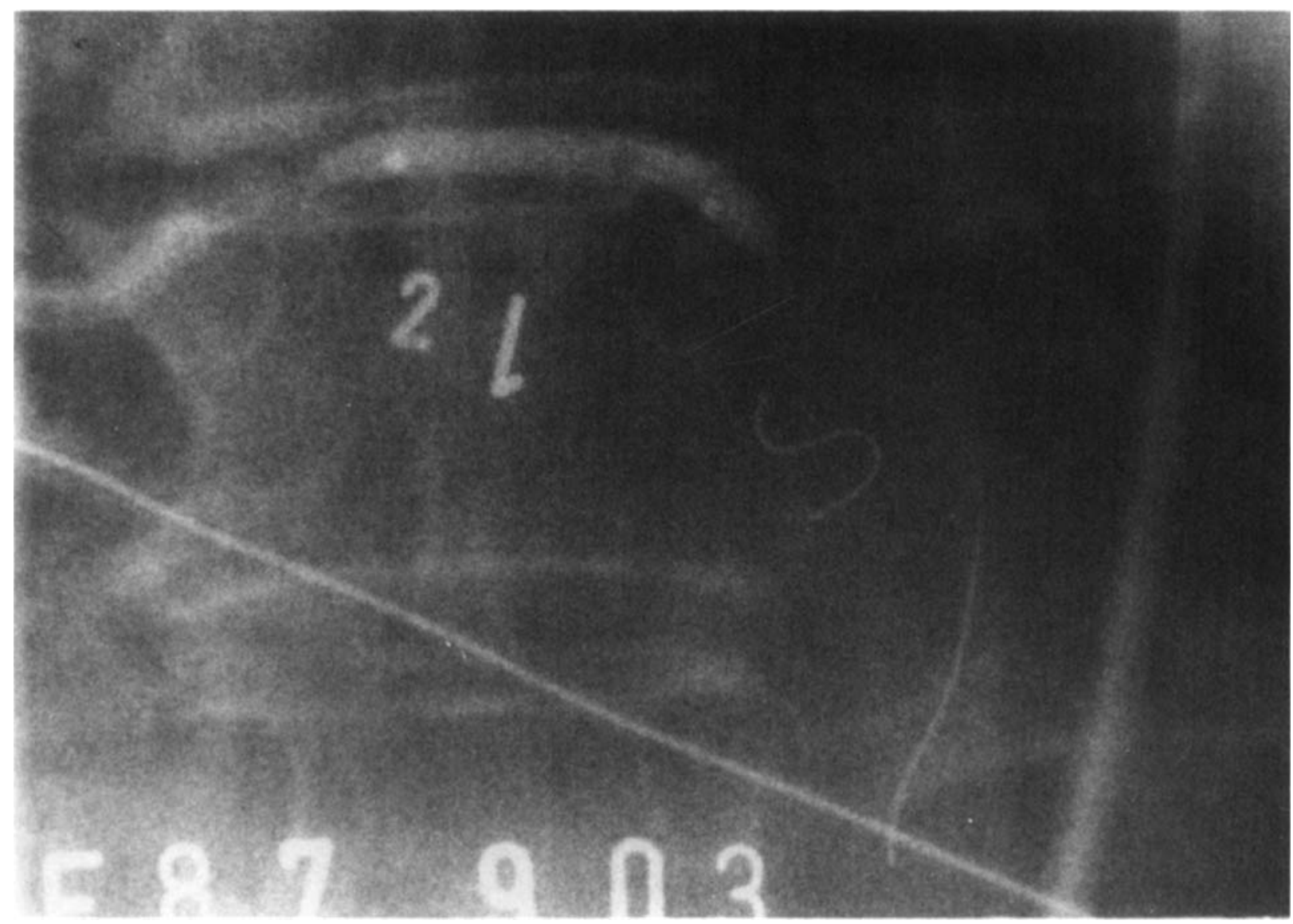

Figure 2B. Angioplasty of the same patient using one guiding catheter and two guidewires. The balloon catheter lies in the left anterior descending artery.

formed and one had a restenosis of the previously dilated graft and died of an infarction 2 years later. Finally, at the time of follow-up, $75 \%$ of the surviving patients of both groups were NYHA Class I.

\section{Discussion}

Patients with LM coronary artery disease comprise between $5 \%$ and $10 \%$ of the patients examined for ischemic heart disease. ${ }^{12-14}$ Their survival with medical therapy has been shown, during the 1970 s, to range between $50 \%-65 \%$ at 3 to 5 years. ${ }^{13-17}$ Since then, therapeutic advances have remarkably helped to improve this ominous prognosis.

Bypass Surgery. Patients with LM disease are now almost always exclusively treated by the sur- geon. The reported long-term survival rates have been consistently over $80 \%$ at 3 to 5 years ${ }^{13,14,15,18}$ with an excellent symptomatic improvement. Nevertheless, according to many early reports of the $1970 \mathrm{~s},{ }^{13,14,19-21}$ there were many subsets of patients in which clearly less benefits could be obtained. These were patients with low grade stenosis severity, normal left ventricular function, left dominancy, normal and dominant RCA, or patients in a low risk category as assessed noninvasively. In addition, the mortality rate of surgery has been relatively high, ranging from $3 \%-11 \%$ in the same studies and it has been even higher (12\%-19\%) when surgery was performed in patients with a left dominant coronary circulation. ${ }^{13,14,21,22}$

In spite of the technical advances of the last decade, this high mortality rate has not decreased, in part due to treatment of more seriously ill and 


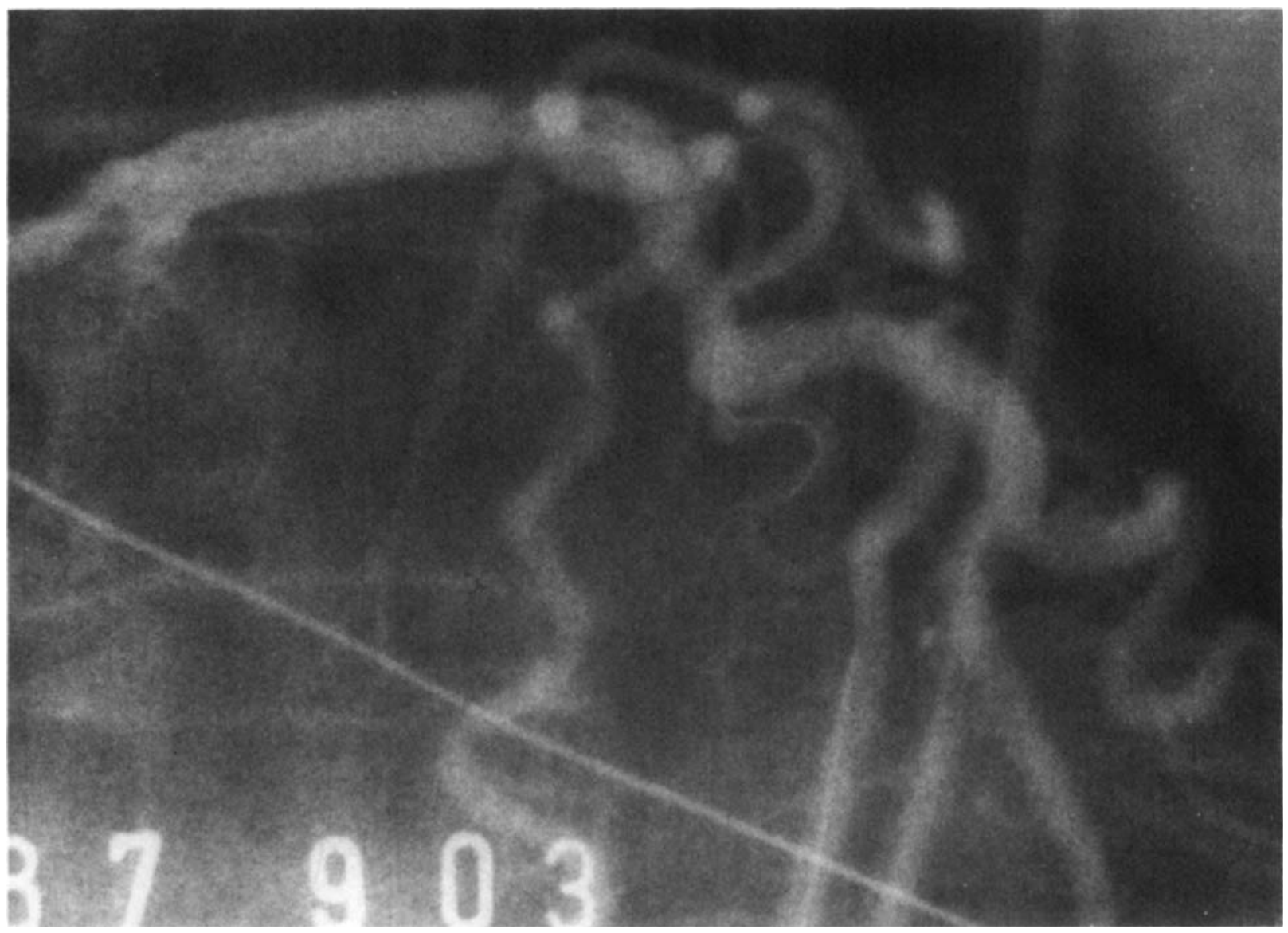

Figure 2C. End result of the procedure.

older patients. ${ }^{22,23}$ Still, LM stenosis remains now one of the most important factors associated with a greater relative survival difference of bypass surgery compared with medical treatment. ${ }^{23,24}$

Coronary Angioplasty. Despite the generally good surgical results, there will continue to be some patients who will be refused surgery for various reasons, and to whom PTCA will be offered. This has been the case of almost all patients reported to date, including those of this report. The reported immediate success rates have been comparable to those of the National Heart, Lung, and Blood Institute (NHLBI) registry for the total population. ${ }^{2}$ Nevertheless, since Grüntzig's first report, ${ }^{25} \mathrm{LM}$ stenosis has been accepted as the most serious PTCA contraindication because of the high risk of the procedure. However, patients with LM disease constitute a heterogeneous group and not all of them share the same hazards. On the one hand, it has been shown, first by Stertzer et al. ${ }^{6}$ and Gershony et al. ${ }^{5}$ and then confirmed by O'Keefe et al. ${ }^{4}$ that patients with so-called "protected" LM (with at least one patent graft or collateral to the left circulation) had an immediate and long-term prognosis comparable to that of the NHLBI registry for the total population. On the other hand, the short- and long-term risk of events in patients with "unprotected" LM has been demonstrated to be prohibitively high, reaching $9 \%$ acute mortality, $65 \%$ late mortality and $23 \%$ late bypass surgery. ${ }^{4}$ Finally, acute LM PTCA in the context of an infarction, while sometimes life-saving, has carried an even more repressive acute mortality rate of $50 \%$.

This Study. The aim of this study was to assess the prognostic value of a known coronary artery 
jeopardy score adapted to LM coronary disease ("risk score"). The risk of LM stenosis relates to the large proportion of muscle at risk from one single occlusive event, ${ }^{26}$ not only before and during PTCA, but also after PTCA if restenosis should occur. Stratification of the disease in "protected" and "unprotected" brings important prognostic information, as we have seen, but it remains mostly qualitative. For example, a patent graft to the left circulation could provide blood flow to the distal LCx only and still be called protective. In the same way, collaterals from the RCA to the left circulation could protect only a diagonal branch or the distal LAD, and so, the amount of myocardium at risk from the LM stenosis and the PTCA would still be important. To offset this problem we theorized that, when the estimated amount of muscle put in jeopardy is greater than that incurred by a single vessel PTCA (risk score of 6 , for proximal LAD), an unacceptable high acute and follow-up event rate should be expected. Thus, our study patients were divided into those with a risk score $\leq 6$ and those with a risk score $>6$, which was easily calculated at the time of cineangiograms review.

There were no baseline differences between the two groups except for ejection fraction that was significantly lower in group I. As expected, this group also contained more patients with previous bypass surgery since it contained slightly more patients with a previous infarction, three-vessel disease, and diseased RCA. This difference is probably a reflection of more severe underlying ischemic cardiac disease. The angiographic success rate was $77 \%$. The danger of LM PTCA is well illustrated by the fact that all angiographic failures terminated in bypass surgery or death. Another point of interest is the high restenosis rate of LM PTCA, as reported by Gershony et al. ${ }^{5}$ or as inferred from the higher risk of restenosis of proximal LAD. ${ }^{27,28}$ Our $50 \%$ restenosis rate supports these observations although it is obviously biased by the small size of the study, the low rate of angiographic follow-up and the fact that repeat angiography was carried out only for recurrence of symptoms of ischemia.

Sophisticated statistical analysis, such as multiple logistic regression, was judged inappropriate because of the small numbers involved and was not applied. Nevertheless, our results with LM PTCA appeared to be easily dichotomized by the risk score. Indeed, at a mean follow-up of 41 months,

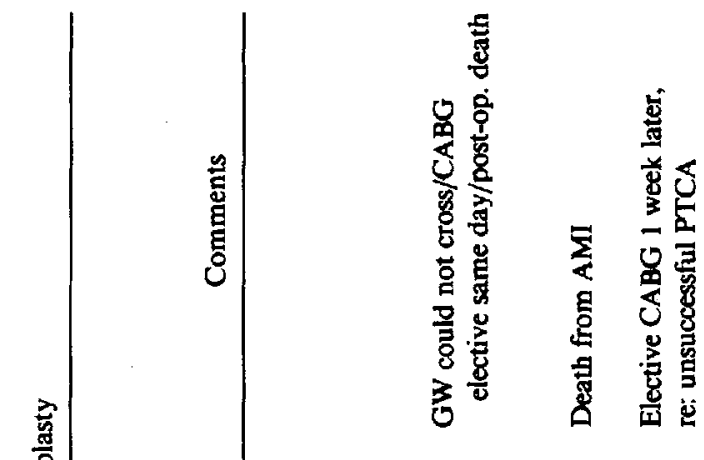

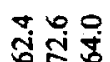

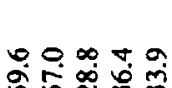

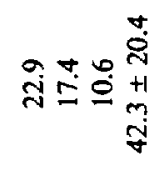

西 \\ 要}

\section{影}

\section{西}


LEFT MAIN ANGIOPLASTY: A NEW RISK SCORE

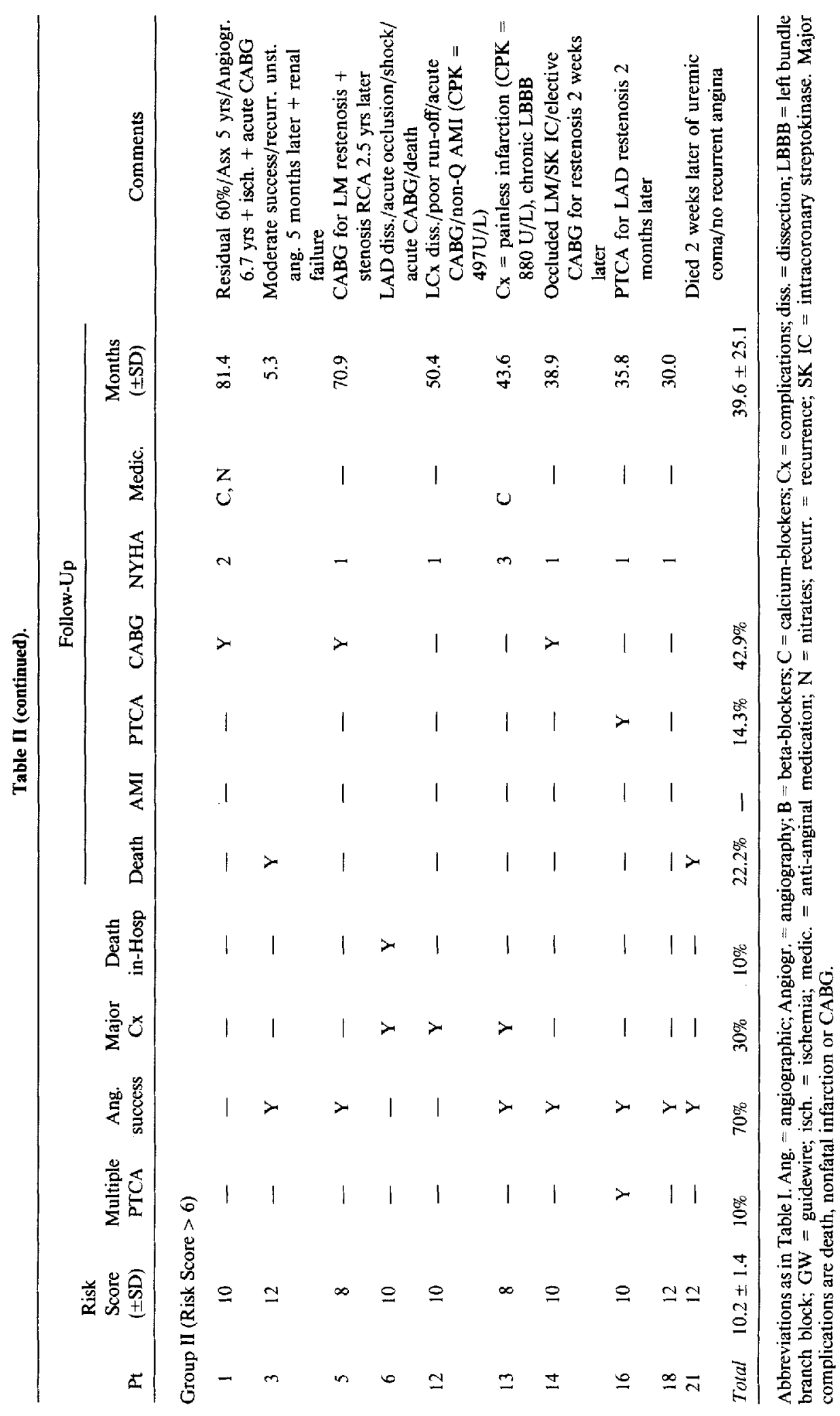




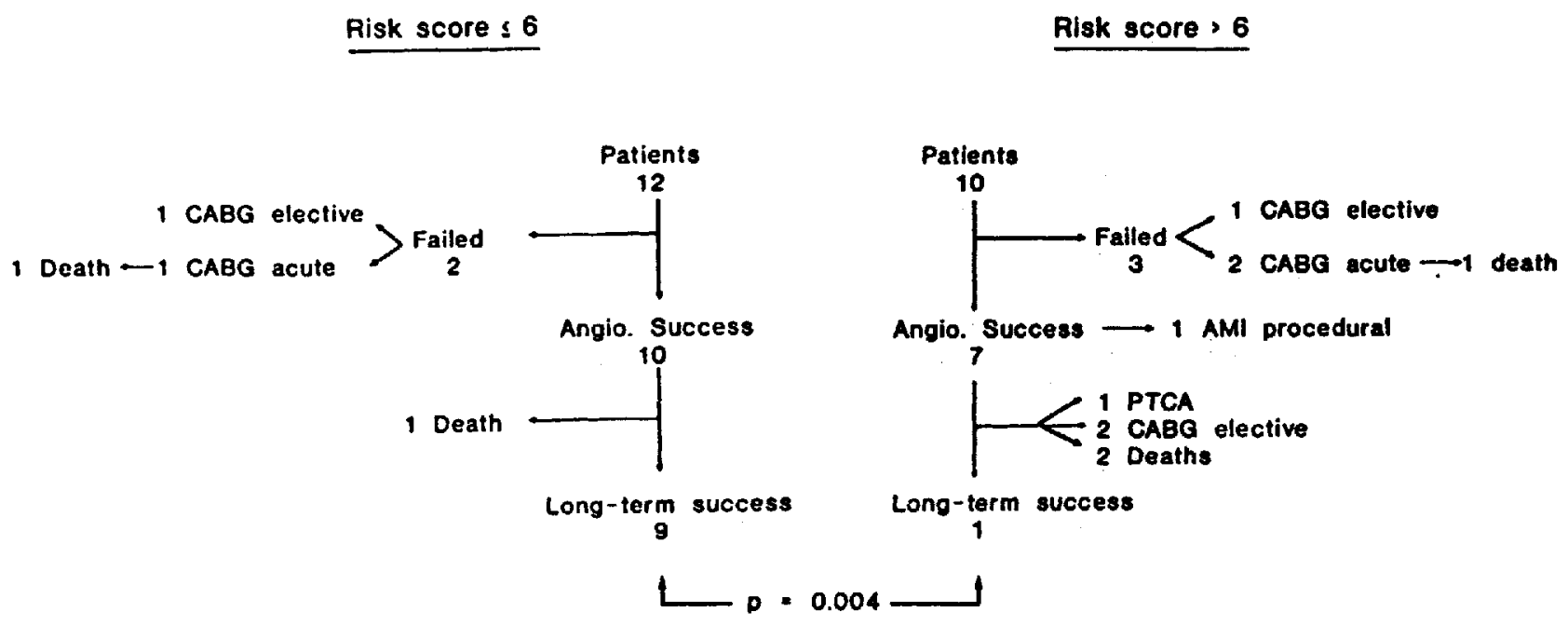

Figure 3. Early and late outcome of left main angioplasty (AMI = acute myocardial infarction; Angio $=$ angiographic; $C A B G=$ coronary artery bypass graft surgery).

$75 \%$ of patients with a risk score $\leq 6$ had persisting long-term success versus $10 \%$ of those with a risk score $>6$ and $83 \%$ versus $70 \%$ were alive. Moreover, when analyzed with simple statistical methods, the risk score predicted accurately the occurrence of acute or follow-up events (Table III). Thus, we concur with the three other studies of LM PTCA that the group of patients evaluated to be at low risk (risk score $\leq 6$ or "protected") have a good prognosis and are reasonable candidates for PTCA. We are also in agreement with the judgement that the high risk patient (risk score $>6$ or "unprotected"), in view of their poor outcome, should not be treated exclusively by PTCA, whenever possible. Regrettably, because of our small sample size, it was not possible to compare adequately both methods of classification. There was a discordance only for patient 5 , who could have been described as protected by his collaterals. Yet, he was actually in the high risk group (risk score $=8$ ) owing to the filling of only the distal LAD. This patient had a bypass operation 2.5 years later. Finally, since our risk score was intended to be a precise but simple method of LM stenosis assessment, potentially useful information such as vessel size and viability of myocardium have not been included in this evaluation.

Adjunctive Treatment and Technical Aspects. Atherosclerosis usually involves the midportion and distal portion of the LM and spares the ostium. ${ }^{12}$ Consequently, proper fitting of the guiding catheter is rarely a problem except for very short anatomical variants where a minimal "controlled" disengagement of the catheter is necessary. ${ }^{4}$ When

Table III. Comparison of Patients With and Without Adverse Acute or Late Events

\begin{tabular}{lccc}
\hline & $\begin{array}{c}\text { No } \\
\text { Acute or } \\
\text { late events }\end{array}$ & $\begin{array}{c}\text { adverse } \\
\text { events }\end{array}$ & P value \\
\hline N (patients) & 12 & 10 & \\
FUP (months) & $38.9 \pm 25.2$ & $43.3 \pm 22.3$ & 0.6 \\
Sex (males) & $9(75 \%)$ & $6(60 \%)$ & 0.6 \\
Age (yrs \pm SD) & $61 \pm 12$ & $66 \pm 10$ & 0.3 \\
Previous AMI & $4(33 \%)$ & $6(60 \%)$ & 0.4 \\
Previous CABG & $4(33 \%)$ & $8(80 \%)$ & 0.04 \\
EF (mean \pm SD) & $0.60 \pm 0.15$ & $0.53 \pm 0.11$ & 0.3 \\
Extent CAD & & & \\
$\quad$ (no. 3VD) & $5(42 \%)$ & $7(70 \%)$ & 0.2 \\
Risk Score & & & \\
$\quad$ (mean \pm SD) & $8.3 \pm 3.4$ & $4.4 \pm 2.9$ & 0.01 \\
Mult. PTCA & $3(25 \%)$ & $4(40 \%)$ & 0.6 \\
Ang. Success & $8(67 \%)$ & $10(100 \%)$ & 0.9 \\
\hline
\end{tabular}

Abbreviations as in previous tables. $\mathrm{CAD}=$ coronary artery disease; Mult. PTCA = multilesion PTCA.

Acute events are death, nonfatal infarction, re-PTCA or CABG. A $P$ value $<0.05$ is considered statistically significant. 


\section{LEFT MAIN ANGIOPLASTY: A NEW RISK SCORE}

the disease is also extending into the bifurcation, a frequent occurrence, a second guidewire in the LCx or LAD may be prudent (Fig. 2). Otherwise, the use of two simultaneous balloons may help to handle a lesion located at the junction of the LM, $\mathrm{LAD}$, and $\mathrm{LCX}$. In the case of patients with an estimated high risk, consideration may also be given to the use of a perfusion balloon catheter, which may permit a better tolerance to inflation. IABP has also been empirically suggested in such patients as a prophylactic measure to lessen the risk of the PTCA, should an acute complication occur. In the series of O'Keefe et al. ${ }^{4}$ and Stertzer et al., ${ }^{6}$ only 11 out of 33 and two out of 11 "unprotected" patients had an IABP, respectively. In our study, only one patient of group II required an IABP because of cardiogenic shock. An even more serious consideration must now be given to the new technique of percutaneous cardiopulmonary bypass support. ${ }^{7}$ Shawl et al. ${ }^{29}$ recently reported 75 high-risk patients among whom were $12 \mathrm{LM}$ and 24 inoperable patients. During the procedure, there were no deaths and there was no need for bypass surgery. There were three in-hospital deaths but the other complications were not reported. However, the same investigators reported earlier their first 43 patients and the femoral complications were frequent: two surgical repairs of femoral arteries, one venous thrombosis, two local infections, two pseudoaneurysms; and two femoral nerves weakness. ${ }^{29}$ Thus, it is not an innocuous technique, and consequently, a precise risk assessment will be mandatory in each LM patient in order to maximize the benefits.

Conclusion. The patient presenting with an LM stenosis remains a challenge to the clinician. The main finding of this study of patients treated with LM PTCA is that a simple risk score, based on the amount of muscle at jeopardy from this lesion, appears to be an important prognostic variable. However, this hypothesis needs to be confirmed with more sophisticated statistical approaches applied to a larger amount of patients. Based on our observations, PTCA seems to be an acceptable treatment option for patients estimated at low risk of events, according to this risk score. On the contrary, patients considered to be at high risk have an alarmingly low long-term success with PTCA. In those patients, surgery should remain the standard therapy.

\section{References}

1. Ryan TJ, Faxon DP, Gunnar RM, et al. Guidelines for percutaneous transluminal coronary angioplasty: A report of the American College of Cardiology/American Heart Association Task Force on assessment of diagnostic and therapeutic cardiovascular procedures. Circulation 1988; 78:486-502.

2. Detre K, Holubkof R, Kelsey S, et al. Percutaneous transluminal coronary angioplasty in 1985-1986 and 1977 1981: The National Heart, Lung, and Blood Institute Registry. N Engl J Med 1988; 318:265-270.

3. Detre K, Holubkof R, Kelsey $S$, et al. One year follow-up results of the 1985-1986 National Heart, Lung, and Blood Institute's percutaneous transluminal coronary angioplasty registry. Circulation 1989; 80:421-428.

4. O'Keefe JH, Hartzler GO, Rutherford BD, et al. Left main coronary angioplasty: Early and late results of 127 acute and elective procedures. Am J Cardiol 1989; 64:144-147.

5. Gershony G, Abi-Mansour P, Wilentz J, et al. Percutaneous transluminal coronary angioplasty of protected and unprotected left main coronary stenosis. J Am Coll Cardiol (abstr.) 1986; 7:238A.

6. Stertzer SH, Myler RK, Insel H, et al, Percutaneous transluminal coronary angioplasty in left main stem coronary stenosis: A five year appraisal. Int J Cardiol 1985; 9:149159.

7. Shawl FA, Domanski MJ, Wish M, et al. Cardiopulmonary bypass supported PTCA: Experience in 75 high risk patients. Circulation (abstr.) 1989; 80:II-271.

8. Califf RM, Phillips HR, Hindman MC, et al. Prognostic value of a coronary antery jeopardy score. $J$ Am Coll Cardiol 1985; 5:1055-1063.

9. De Feyter PJ. Coronary angioplasty for unstable angina. Am Heart J 1989; 118:860-868.

10. Meier B. Kissing balloon angioplasty. Am J Cardiol 1985 54:918-920.

11. Holmes DR, Vlietstra RE, Smith HC, et al. Restenosis after percutaneous transluminal coronary angioplasty (PTCA): A report from the PTCA Registry of the National Heart, Lung, and Blood Institute. Am J Cardiol 1984; $53: 77 \mathrm{C}-81 \mathrm{C}$.

12. Conti CJ, Selby JH, Christie LG, et al. Left main coronary artery stenosis: Clinical spectrum, pathophysiology, and management. Prog Cardiovasc Dis 1979: 22:73-106.

13. Takaro $T$, Peduzzi $P$, Detre KM, et al. Survival in subgroups of patients with left main coronary artery disease: Veterans Administration Cooperative Study of Surgery for coronary arterial occlusive disease. Circulation 1982; 66:14-22.

14. Chaitman BR, Fisher LD, Bourassa MG, et al. Effect of coronary bypass surgery on survival patterns in subsets of patients with left main coronary artery disease: Report of the collaborative study in Coronary Artery Surgery (CASS). Am J Cardiol 1981; 48:765-777.

15. Prospective randomized study of coronary artery bypass surgery in stable angina pectoris. Second interim report by the European Coronary Surgery Study Group. Lancet 1980;1:492-495.

16. Lim JS, Proudfit WL, Sones FM. Left main coronary arterial obstruction: Long-term follow-up of 141 nonsurgical cases. Am J Cardiol 1975; 36:131-135.

17. Conley MJ, Ely RL, Kisslo J, et al. The prognostic spectrum of left main stenosis. Circulation 1978; 57:947-952.

18. Taylor HA, Deumite NJ, Chaitman BR, et al. Asymptomatic left main coronary artery disease in the Coronary Ar- 


\section{SAMSON, ET AL.}

tery Surgery Study (CASS) Registry. Circulation 1989; 79:1171-1179.

19. Campeau L, Corbara F, Crochet D, et al. Left main coronary artery stenosis: The influence of aortocoronary bypass surgery on survival. Circulation 1978; 57:1111-1115.

20. Talano JV, Scanlon PJ, Meadows WR, et al. Influence of surgery on survival in 145 patients with left main coronary artery disease. Circulation 1975; 51(Suppl 1):I-105-I-1 I I.

21. Gomberg J, Klein LW, Seelaus P, et al. Surgical revascularization of left main coronary artery stenosis: Determinants of peri-operative and long-term outcome in the 1980s. Am Heart J 1988; 116:440-446.

22. Chaitman BR, Rogers WJ, Davis K, et al. Operative risk factors in patients with left main coronary-artery disease. N Engl J Med 1980; 303:953-957.

23. Califf RM, Harrell FE, Lee KL, et al. The evolution of medical and surgical therapy for coronary artery disease: A 15-year perspective. J Am Med Assoc 1989; 261:20772086.

24. Vigilante GJ, Weintraub WS, Klein LW, et al. Medical and surgical survival in coronary artery disease in the 1980s. Am J Cardiol 1986; 58:926-931.

25. Grüntzig AR, Senning A, Siegenthaler WE. Nonoperative dilatation of coronary artery stenosis: Percutaneous transluminal coronary angioplasty. N Engl J Med 1979; 301:61-68.

26. Hutter AM. Is there a left main equivalent? Circulation $1980 ; 62: 207-211$.

27. Mata LA, Bosch X, David PR, et al. Clinical and angiographic assessment 6 months after double vessel percutaneous coronary angioplasty. J Am Coll Cardiol 1985; 6:1239-1244.

28. Leimgruber PP, Roubin GS, Hollman J, et al. Restenosis after successful coronary angioplasty in patients with single-vessel disease. Circulation 1986; 73:710-717.

29. Shawl FA, Domanski MJ, Punja S, et al. Percutaneous institution of cardiopulmonary (bypass) support: Technique and complications. J Am Coll Cardiol (abstr.) 1989; 13:159A. 